\title{
haseENDER
}

Trascender, Contabilidad y Gestión Núm. 10 (enero - abril del 2019).

ISSN: 2448-6388. Universidad de Sonora. Departamento de Contabilidad.

Reserva de Derechos 04-2015-04172070800-203.

\section{Análisis teórico de los componentes que integran el modelo de Gobierno abierto en México}

Theoretical analysis of the components that make up the model of open Government in Mexico

\section{Guadalupe Durazo Armenta ${ }^{1}$}

\section{Resumen}

El término Transparencia en la administración pública significa la forma en que los funcionarios públicos de las Entidades que componen los tres niveles de gobierno dan a conocer a la ciudadanía la forma en gastan los recursos, a través de la rendición de cuentas es la manera que se obliga a demostrar y justificar que realmente fueron utilizados para su fin, por medio de las nuevas tecnologías, la participación ciudadana es más proactiva, siendo así más estrecha la relación de la información de la administración pública y la ciudadanía, es así que con estos elementos nace el modelo de gobierno abierto en México.

Palabras clave: transparencia, gobierno abierto, rendición de cuentas.

DOI: https://doi.org/10.36791/tcg.v10i0.57

JEL: H83 Administración Pública.

Recibido: 20 de diciembre de 2018.

Aceptado: 4 de abril de 2019.

\begin{abstract}
The term Transparency in public administration means the way in which the public officials of the Entities that make up the three levels of government inform the public about the way in which resources are spent, through accountability is the way it is it forces us to demonstrate and justify that they were really used for their purpose, through new technologies, citizen participation is more proactive, and the relationship of public administration information and citizenship is closer, so with these elements the model of open government in Mexico is born.
\end{abstract}

Keywords: transparency, open government, accountability. 


\section{Introducción}

En el presente trabajo daremos a conocer la historia y definiciones desde varias perspectivas de los componentes del gobierno abierto, así como una introducción de lo que este modelo es en México y sus funciones. La información se obtuvo a través de investigar en varias revistas científicas de autores mexicanos, así como de otros países.

Hace algunos años, México siguió el ejemplo de varios países de Europa y América del Norte y creo sus propias leyes de acceso a la información, ha creado instituciones y mecanismos con la finalidad de facilitar a los ciudadanos el acceso a la información que genera el gobierno. En este artículo vamos a presentar un poco de la historia de los componentes que según el Instituto Nacional de Acceso a la Información INAI, contribuyen a un modelo de gobierno abierto siendo el INAI un organismo autónomo garante del acceso a la información, contribuye en la coordinación de actividades que permitan atender las demandas apremiantes de la sociedad en materia de transparencia, participación y apertura institucional para disminuir así la crisis existente por la falta de confianza de los ciudadanos hacia las instituciones gubernamentales. Esta labor institucional que inició con la Alianza por el Gobierno Abierto (AGA) hace cerca de seis años, hoy se refuerza a nivel local con el impulso de esta agenda en diferentes estados de la República Mexicana (INAI, 2019).

Los componentes que integran el modelo de gobierno abierto son:

- Transparencia

- Rendición de Cuentas

- Participación Ciudadana

- Innovación

\section{Transparencia}

En el presente artículo vamos a ver diferentes puntos de vista el concepto de transparencia, para conocer los términos desde la perspectiva de varios autores y así formarnos un panorama más amplío de este componente, para (Ramos Tovar, M. E., Sieglin, V., \& Zúñiga Coronado, M. 2013. 26-45) consideran que es necesario hacer mención de los puntos clave que nutrieron su concepción, en primer lugar, la transparencia, “cobró fuerza en Finlandia (1951), Estados Unidos (1966) y Dinamarca (1970), para volverse luego parte de la oleada democratizadora en los últimos cinco años del siglo XX, periodo en el cual más de 40 países del mundo tomaron su ejemplo e instituyeron sus propias leyes de acceso a la información” (Bustamante, 2007). Lo cual implicó que México no dejara escapar el momento para integrarse a la tendencia y crear su propia legislación, sin embargo, antes de llegar a su consolidación, sucedieron diversos acontecimientos que lograron su materialización.

Para Ugalde, L. C. (2003), 5-51. La transparencia es una característica que abre la información de las organizaciones políticas y burocráticas al escrutinio público mediante sistemas de clasificación y difusión que reducen los costos de acceso a la información del gobierno. Sin embargo, la transparencia no implica un acto de rendir cuentas a un destinatario específico, sino la práctica de colocar la información en la "vitrina pública” para que los interesados puedan revisarla, analizarla y, en su caso, usarla como mecanismo para sancionar en caso de que haya anomalías en su interior.

Existen diversas opiniones como las de (Alberto, J., \& Rodríguez, M. 2016: 55). terminada la guerra, vencido Hitler y su Tercer Reino, el concierto de naciones aprobó la Declaración Universal de Derechos Humanos para requerir a todos los Estados algo que se daba por sentado en los regímenes democráticos hasta que ocurrió la barbarie Nazi: 
Todo individuo tiene derecho a la libertad de opinión y de expresión; este derecho incluye el de no ser molestado a causa de sus opiniones, el de investigar y recibir informaciones $y$ opiniones, $y$ el de difundirlas, sin limitación de fronteras, por cualquier medio de expresión.

Asimismo, según Martínez, M. (2014: 203-215). Es menester revisar la trascendencia que el derecho a la información ha tenido en nuestro sistema jurídico, el cual se encuentra consagrado en el Artículo $6^{\circ}$ de la Ley Fundamental, precepto que pasó de la Constitución de 1857 a la de 1917 en sus términos. La primera reforma tuvo lugar en diciembre de 1977 bajo el marco de la denominada Reforma Política; sentó las bases del derecho a la información al adicionar en el Artículo 6 constitucional, como parte de las garantías individuales, "el derecho a la información [como garantía del] Estado” (Larrañaga, 2008).

Según, Loredo, J. de J. M. (2016: 14-26). el derecho a la información y su garantía estatal se encuentran consagrados en el Artículo $6^{\circ}$ de la Constitución Política de los Estados Unidos Mexicanos; sin embargo, su texto dista mucho del original publicado en 1917, retomado en sus términos de la ley fundamental de 1857, el cual no consideraba dicho derecho. A saber:

"La manifestación de las ideas no será objeto de ninguna inquisición judicial o administrativa, sino en el caso de que ataque a la moral, los derechos de terceros, provoque algún delito, o perturbe el orden público".

En La cuarta reforma al Artículo $6^{\circ}$ constitucional se publicó en el Diario Oficial de la Federación el 11 de junio de 2013 y ordena que:

[...) toda persona tiene derecho al libre acceso a información plural y oportuna, así como a buscar, recibir y difundir información e ideas de toda índole por cualquier medio de expresión.
El Estado garantizará el derecho de acceso a las tecnologías de la información y comunicación, así como a los servicios de radiodifusión y telecomunicaciones, incluido el de banda ancha e internet. Para tales efectos, el Estado establecerá condiciones de competencia efectiva en la prestación de dichos servicios.

Para los autores Vera Martínez, M. C., Rocha Romero, D., \& Martínez Rodríguez, M. C. (2015) Tal como se ha señalado, la transparencia como política pública facilita el acto comunicativo y una relación más comprensiva entre los seres humanos al tiempo que permite ejercer vigilancia. Sin embargo, las políticas de transparencia no necesariamente evitan o disminuyen el fenómeno de la corrupción. Latinoamérica, en este sentido, es un ejemplo regional de sendas experiencias relacionadas con sucesos de corrupción política. Por ello, para ayudar a los gobiernos, sectores privados y por sobre todo a otros interesados en la sociedad civil, se ha creado un organismo no gubernamental llamado Transparency International (TI) para combatir la corrupción a través de una red de capítulos en más de 90 países. Dicha entidad ha estado publicando el Índice de Percepción de Corrupción (IPC) con creciente precisión y cobertura.

Martínez, M. (2014: 203-215). Afirma que la transparencia también ayuda a tener procesos documentados que en conjunto generan información asimétrica para facilitar a los ciudadanos su intervención en procesos de decisiones, así como su identificación de cada decisión tomada por las autoridades. Queda claro hasta aquí que el acceso a la información, la transparencia y rendición constituyen un trípode indispensable y necesario para el desarrollo democrático y para dar cauce al Estado de Derecho.

Rosales García, C. M. (2013: 113-137). Hace mención que es menester mencionar, que el derecho a la información no es absoluto. Las restricciones a esta prerrogativa son: 
“1) la moral pública, especialmente la protección de grupos vulnerables (niños $y$ jóvenes);

\section{2) la seguridad nacional;}

3) la defensa del Estado democrático;

4) el orden y la seguridad pública, y

5) la salud pública. Por otro lado, las libertades contenidas en el derecho a la información pueden entrar en colisión con el derecho a la intimidad o vida privada, y el derecho al honor y la reputación” (López, 2001, págs. 170-171).

El Manual de Vinculación del SNT y SNA definen a la Transparencia como: Instrumentos normativos y prácticas de gestión orientados a asegurar la apertura de procesos y la disponibilidad de la información custodiada por las organizaciones gubernamentales. La transparencia es un componente esencial del Gobierno Abierto, ya que, a través de ella, se eliminan obstáculos y costos de información, para que los ciudadanos accedan a información que les permita generar conocimiento público e incidir en las actividades gubernamentales. USAID ( $\sin$ fecha).

\section{Rendición de Cuentas}

Otro de los componentes del modelo de gobierno abierto, que es la rendición de cuentas para, Ugalde, L. C. (2003). Significa "la obligación de todos los servidores públicos de dar cuentas, explicar y justificar sus actos al público, que es el último depositario de la soberanía en una democracia”. Para McLean, la rendición de cuentas es "el requerimiento para que los representantes den cuenta y respondan frente a los representados sobre el uso de sus poderes y responsabilidades, actúen como respuesta a las críticas o requerimientos que les son señalados y acepten responsabilidad en caso de errores, incompetencia o engaño”.

Jerry L. Mashaw (2016) defiende la idea de concebirla como un "régimen de rendición de cuentas" por la formulación de las siguientes 6 preguntas (ver figura 1).

Figura 1. Interpretación del régimen de rendición de cuentas de Mashaw

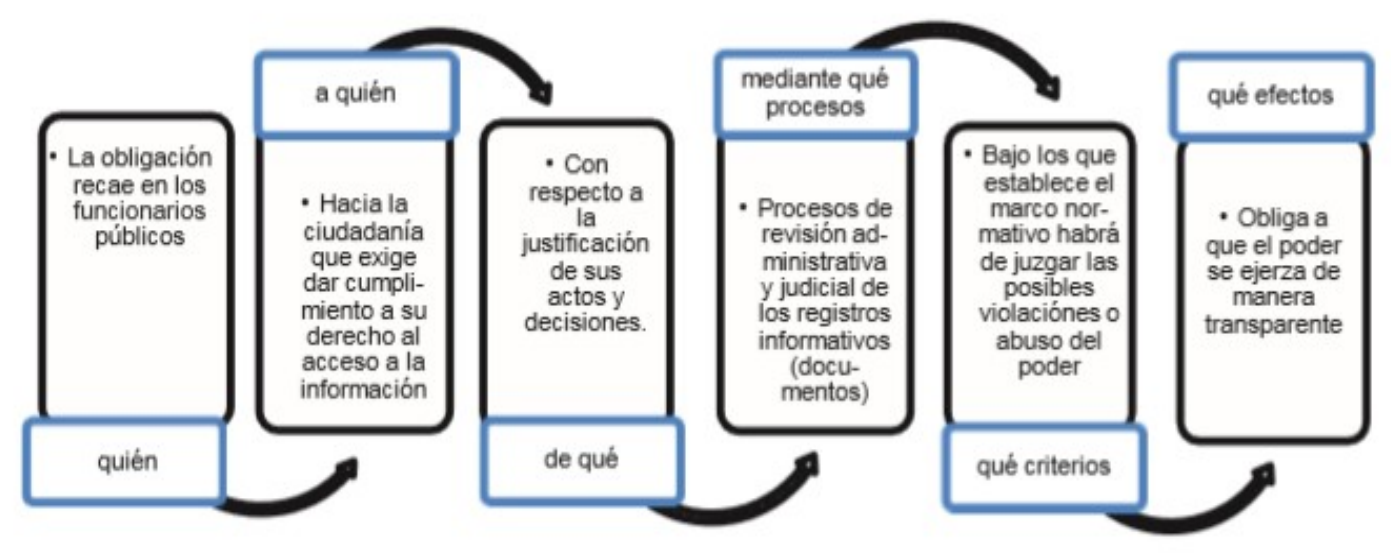

Fuente: Elaboración propia con base en Mashaw, 2016. 
Para, Ramírez, A. M., \& Alejandra, H. C. J. (2014) 79-104. Se puede decir que la rendición de cuentas es la obligación que tienen los representantes del poder, tanto políticos como funcionarios, de mantener a disposición la información que generan, porque ante el entendido de que esta última es de carácter público, la sociedad tiene el derecho de conocer la comprobación de sus actos y decisiones realizadas en función de sus obligaciones. Ambos aspectos, justificación de los actos y decisiones, se constituyen en registros documentales que revelan la naturaleza de su propia creación.

En el Manual de vinculación para el SNT y el SNA definen a la rendición de cuentas como procesos y actividades de control, seguimiento, vigilancia que permite a los ciudadanos monitorear, evaluar y exigir cuentas a autoridades y funcionarios gubernamentales. El control y la vigilancia del gobierno por parte de la ciudadanía puede llevarse a cabo a través de tres modalidades esenciales a través del voto (rendición de cuentas vertical), de instancias de control y vigilancia especializadas con capacidades de verificación y sanción (rendición de cuentas horizontal), o del involucramiento directo de la ciudadanía en actividades de control administrativo (rendición de cuentas diagonal). USAID (sin fecha).

Asimismo, Schedler (2009: 12) 5-37. Señala que la rendición de cuentas se sustenta en tres ejes, a través de los cuales se puede:

1. Prevenir y corregir abusos de poder.

2. Obligar al poder a someterse al escrutinio ciudadano.

3. Forzarlo a explicar sus actos y someterlo a sanciones.

Los autores, Villalpando, T., \& Andrés, E. (2009) 7189. Afirman que La rendición de cuentas puede ser de dos tipos, horizontal y vertical, la primera se refiere a las relaciones de control entre las agencias gubernamentales, mientras que la segunda, se refiere a la posibilidad del control de la sociedad hacia el Estado (Schedler, 2004: 33). O’Donnel, citado por Ugalde (2002), entiende que la rendición de cuentas horizontal debe realizarse en un esquema de división de poderes, sistema de pesos y contrapesos en el que no prevalece ningún poder sobre otro. El accountability horizontal supone la vigilancia de los órganos estatales por parte de otras instancias estatales, lo suficientemente autónomas e independientes para desarrollar tareas de fiscalización. El accountability vertical, también llamada rendición de cuentas política, por su parte, está fundamentada en las garantías individuales de libertad de expresión y asociación, lo que permite que los ciudadanos se organicen para defender causas e impugnar las decisiones gubernamentales, así como la promoción del cambio político como sanción, o la dotación de incentivos o ratificación como estímulo positivo (Vaughn, 2000).

Para Schedler, A. (2004: 5-37). Los tres aspectos en su conjunto -información, justificación y castigoconvierten a la rendición de cuentas en una empresa multifacética. La convierten en una casa conceptual amplia que hospeda una muchedumbre de términos afines, como la vigilancia, la auditoría, la fiscalización o la penalización, y todos comparten la pretensión de domesticar el ejercicio del poder. El atractivo de la rendición de cuentas deriva de su amplitud, el concepto es comprensivo. Lejos de denotar una técnica puntual para domesticar al poder, la rendición de cuentas abarca de manera genérica tres maneras diferentes para prevenir y corregir abusos de poder: obliga al poder a abrirse a la inspección pública; lo fuerza a explicar y justificar sus actos, y lo supedita a la amenaza de sanciones. (Ver Figura 2). 
Figura 2. Rendición de cuentas.

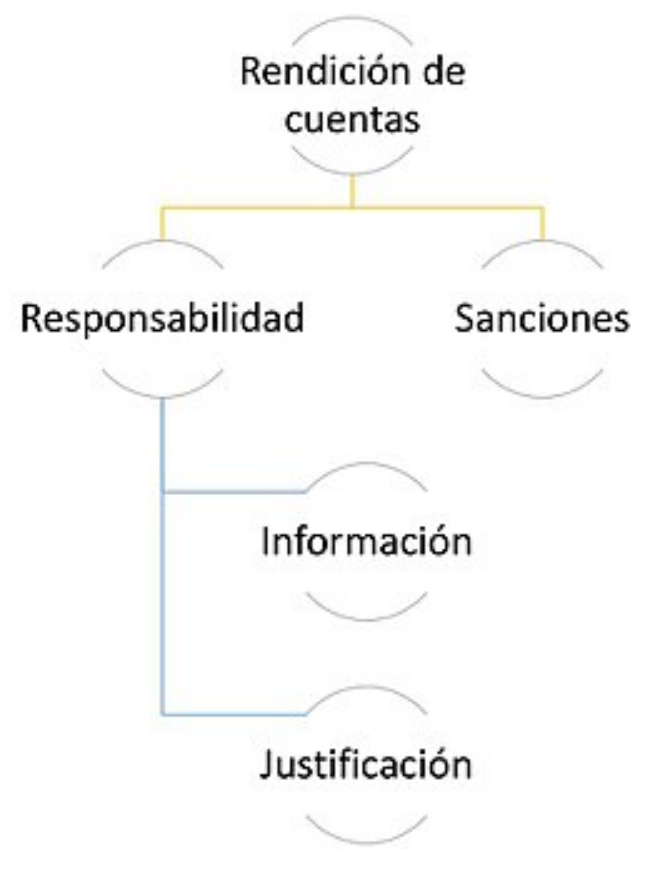

Fuente: Schedler, A., 2004.

La "responsabilidad" como nuestro punto de partida. Como sugiere esta noción, rendir cuentas implica la obligación de responder a preguntas incómodas; y al revés, exigir cuentas implica la oportunidad de hacer preguntas incómodas. ¿Pero qué clase de preguntas? En principio, las agencias de rendición de cuentas pueden averiguar dos tipos de cosas. Pueden pedirles a los funcionarios públicos que informen sobre sus decisiones o les pueden pedir que expliquen sus decisiones. Pueden preguntar por hechos (la dimensión informativa de la rendición de cuentas) o por razones (la dimensión argumentativa de la rendición de cuentas).

En inglés, la noción correspondiente es enforcement, otro término que carece de equivalente preciso en castellano y que describe un conjunto de actividades orientadas hacia la observancia de la ley. Quiere decir, en esencia: hacer valer la ley, si es necesario por la fuerza.
Lo que nos importa aquí es su aspecto impositivo, el esfuerzo por asegurar el cumplimiento con las normas por medio de la imposición de sanciones. Ello implica que los actores que exigen cuentas no solamente “cuestionan”, “eventualmente” también “castigan” el comportamiento impropio de servidores públicos (O’Donnell 1994: 61; Schedler, A., 2004: 5-37).

A través de la e-Transparencia y la e-Rendición de cuentas la corrupción puede ser combatida en el gobierno, al introducirse en los sitios web procesos computarizados que regulen su funcionamiento y eviten la tentación de los servidores públicos para recibir o exigir pagos y a los ciudadanos para ofrecerlos. Si bien la corrupción no se ha eliminado totalmente, ha disminuido. (Quintanilla, 2012; 95-119). 


\section{Participación ciudadana}

La participación ciudadana, según Alicia Ziccardi ofrece un par de conceptos, como muestra de otros más. En el primer caso, se subraya la importancia que tiene el ciudadano como ese miembro de la ciudad interesado en los asuntos de carácter público en donde su intervención tiene como misión representar los intereses que le son particulares al conjunto de habitantes o de ciudadanos que comulgan en un determinado interés también de índole público. "La participación ciudadana, a diferencia de otras formas de participación, refiere específicamente a que los habitantes de las ciudades intervengan en las actividades públicas representando intereses particulares (no individuales)" (Ziccardi, 1998: 32). Sánchez M. (2009: 85-102).

La gestión gubernamental sin la participación ciudadana se convierte en autoritaria y alejada de las necesidades sentidas de la ciudadanía. La gobernabilidad está garantizada cuando el ciudadano se hace presente y con su participación pondera la arena política. La participación del ciudadano obliga a que la autoridad sea responsable y ofrezca la rendición de cuentas tan necesaria para la transparencia de una gestión, de un buen gobierno, lo que permitirá impulsar lo que está en cuestión: la calidad de vida. Sánchez M. (2009: 85-102).

Según González, Juan, Sánchez, J. (2015) 51-73. Una de las innovaciones más recientes ha sido la introducción de acciones dirigidas a promover la participación directa de los ciudadanos en los asuntos públicos locales a través de arreglos institucionales diversos. Los teóricos de la participación política en ocasiones parecen olvidar que los nuevos mecanismos participativos se incorporan en un contexto institucional preexistente, basado en principios diferentes, y que los procesos de encaje suelen implicar importantes fricciones y conflictos (Salvador y Ramió, 2012: 1). Los gobiernos cerrados están acostumbrados a bloquear las modalidades de la participación ciudadana, por lo que los escasos mecanismos institucionalizados de consulta están controlados por sus propias reglas de control. Por el contrario, los gobiernos abiertos deben destacarse por su nivel de transparencia, rendición de cuentas, mecanismos de participación ciudadana e integridad pública. Es importante considerar estos elementos para mejorar la participación ciudadana, como se observa en el cuadro 1. 
Cuadro 1. Propuesta para mejorar la participación ciudadana.

\begin{tabular}{|l|l|}
\hline \multicolumn{1}{|c|}{ Propuesta } & \multicolumn{1}{c|}{ Descripción } \\
\hline $\begin{array}{l}\text { La información es un requisito previo } \\
\text { básico }\end{array}$ & $\begin{array}{l}\text { Lograr adecuados niveles de acceso a la información y de protección } \\
\text { de ésta requiere una normativa apropiada, mecanismos institucionales } \\
\text { claros para aplicarla y un sistema judicial independiente que garantice } \\
\text { su cumplimiento. }\end{array}$ \\
\hline $\begin{array}{l}\text { La consulta es fundamental para la } \\
\text { elaboración de políticas }\end{array}$ & $\begin{array}{l}\text { En la consulta, los poderes públicos definen cuestiones, establecen } \\
\text { preguntas, gestionan el proceso e invitan a los ciudadanos a contribuir } \\
\text { con sus puntos de vista y opiniones. }\end{array}$ \\
\hline $\begin{array}{l}\text { La participación activa supone una } \\
\text { nueva frontera. }\end{array}$ & $\begin{array}{l}\text { La participación activa reconoce la capacidad y la autonomía de los } \\
\text { ciudadanos para debatir y generar alternativas de políticas. Se precisa } \\
\text { que los ciudadanos asuman un mayor grado de responsabilidad en la } \\
\text { elaboración de políticas, como contrapartida de los mayores derechos } \\
\text { de participación que gozan. }\end{array}$ \\
\hline Atraer a los ciudadanos en línea. & $\begin{array}{l}\text { Todos los países de la OCDE reconocen el enorme potencial de las } \\
\text { Tecnologías de la Información y la Comunicación (TIC) para ofrecer } \\
\text { un servicio público de mayor calidad a precios más bajos; mejora la } \\
\text { transparencia y la rendición de cuentas de los poderes públicos. }\end{array}$ \\
\hline
\end{tabular}

Fuente: González \& Sánchez, 2015.

Los ciudadanos, cada vez más capacitados e informados, exigen que sus opiniones y conocimientos se reflejen en la toma de decisiones, exigencia que los gobiernos deberán responder imperativamente. Informar, consultar y hacer participar a los ciudadanos constituyen los pilares de todo buen gobierno, los medios adecuados de fomentar la apertura, y una buena inversión para mejorar la elaboración de políticas públicas. Estos tres aspectos permiten a los poderes públicos obtener nuevas fuentes de ideas, información y recursos para la toma de decisiones. Además, contribuye a desarrollar la confianza del público en la administración pública, lo que incrementa la calidad de la democracia y fortalece el civismo (Caddy y Vergez, 2003: 4-5).
La participación ciudadana deberá ser considerada por los niveles de gobierno (federal, estatal y municipal) como un derecho efectivo y que, en su marco legal, deberá expresarse de forma clara y congruente con los nuevos escenarios de alternancia política y de calidad de la democracia. La participación ciudadana es formar parte activa de los asuntos del gobierno y en la construcción del espacio público. La Alianza por el Gobierno Abierto (AGA), de la cual México es miembro fundador y activo, establece como estrategias centrales la transparencia, la participación ciudadana, la colaboración y la integridad pública. 
En este marco de referencia, los niveles de gobierno mexicano, deben realizar mayores compromisos con la participación ciudadana, que permitan el involucramiento de mayores segmentos de la ciudadanía que permitan participar en todo el ciclo de las políticas públicas. González, Juan, Sánchez, J. (2015: 51-73).

La participación ciudadana es, por lo tanto, un eje transversal y continuo en las políticas públicas, que debe ser previsto por la administración, quien no solo debe prepararse para recibir las actuaciones del administrado y crear las condiciones y los espacios para que se dé durante todas las fases del ciclo de políticas públicas: formulación, planificación, ejecución, seguimiento, evaluación y control, ello aplicado a todos los niveles del Estados: nacional, regional y local. Arroyo Chacón, J. I. (2017: 13-41).

Font y Blanco (2006: 38) definen la participación ciudadana como "todas las actividades que los ciudadanos realizan voluntariamente -ya sea a modo individual o a través de sus colectivos y asociacionescon la intención de influir directa o indirectamente en las políticas públicas y en las decisiones de los distintos niveles del sistema político y administrativo”. PrietoMartín, Pedro; Ramírez-Alujas, Á. (2014: 61-100).

\section{Innovación}

Expertos en la materia, como Brugué, Blanco \& Boada (2014), señalan dos requerimientos para generar innovación en el ámbito público: la innovación sustantiva, como el primer requisito, pues parte de la necesidad de cuestionar el viejo conocimiento. Para innovar es necesario que la institución se autocuestione, que cuente con una visión introspectiva que le permita dudar de sus procesos, actuaciones, mecanismos establecidos, junto a una mente amplia que permita el cambio. Mientras no se reconozca esta necesidad, no existirá innovación. Como segundo requisito, la innovación debe ser colectiva. La innovación pública se genera a partir del conocimiento colectivo, de todo el funcionariado y de la ciudadanía, de allí que actualmente se hable innovación abierta en un marco de gobierno abierto. (Arroyo Chacón, J. I. (2017: 13-41).

La innovación pública actualmente se considera un principio del nuevo modelo de gestión pública, un pilar del gobierno abierto, pues es a partir de la apertura, de los procesos de participación entre administración pública y ciudadanía, que se genera la innovación, tal y como lo consagra la Carta Iberoamericana de Gobierno Abierto cuando dice:

i) Principio de innovación pública: supone promover e impulsar nuevas metodologías, procesos, procedimientos y herramientas que permitan aprovechar ideas y crear valor público, especialmente mediante el uso de las tecnologías de la información y comunicación y la constante adaptación de su funcionamiento y estructura a las nuevas necesidades (Centro Latinoamericano de administración para el Desarrollo (CLAD), 2016). (Arroyo Chacón, J. I. (2017: 13-41).

\section{Evolución del término Gobierno Abierto}

Sandoval-Almazán, R. (2015: 203-227). Expone que el gobierno abierto existe desde el siglo XVI cuando fue establecido en Suecia y los datos gubernamentales fueron hechos públicos como un derecho constitucional; así, la gente pudo tener acceso a esta información (Tauberer, 2012). Parks (1957) escribió un artículo en la revista de Derecho de George Washington, que se tituló: "The Open Government principle: applying the right to know under the constitution", donde comienza su argumentación señalando que tanto el partido demócrata como el republicano habrían prometido impulsar una libertad de información del gobierno de Estados Unidos, pero que no se había cumplido. Esta solicitud es una reacción al hecho de que se ocultara información militar durante la Segunda Guerra Mundial y constituyó el punto de arranque para comenzar a definir lo que es un gobierno abierto. 
Según Arroyo Chacón, J. I. (2017: 13-41). El término gobierno abierto cobra relevancia en el año 2009, debido a la iniciativa del entonces presidente de los Estados Unidos, Barack Obama, en el Memorando sobre Transparencia y Gobierno Abierto; ello sin desconocer que ya existían algunas experiencias en este sentido, como las leyes de acceso a la información pública aprobadas por Gran Bretaña en los años setenta y otras previas. Pero, sin duda, es a partir del 2009 que este paradigma emerge sobre la mesa de discusión. Iniciativa que tuvo un gran impulso gracias a la creación, en 2011, de la Alianza para el Gobierno Abierto (Open Government Partnership, OGP) a la que hoy pertenecen 60 países y cuenta con un mecanismo independiente para evaluar el grado de avance de cada gobierno en torno a los planes que presenta para implementar el gobierno abierto en sus administraciones públicas.

\section{Definición}

Un gobierno abierto es aquel que entabla una constante conversación con los ciudadanos con el fin de escuchar lo que ellos dicen y solicitan, que toma decisiones basadas en sus necesidades y teniendo en cuenta sus preferencias, que facilita la colaboración de los ciudadanos y funcionarios en el desarrollo de los servicios que presta, y que comunica todo lo que decide y hace de forma abierta y transparente (Calderón, 2012: 27). Así, un gobierno abierto sería aquel en el que las empresas, las organizaciones de la sociedad civil (OSC) y los ciudadanos pueden "saber cosas" (obtener información relevante y comprensible), "conseguir cosas" (obtener servicios y realizar transacciones desde y con el gobierno), y "crear cosas" (participar en el proceso de toma de decisiones (Ramírez y Dassen, 2012: 43). (González, Juan, Sánchez, J. (2015: 51-73).

La OCDE propone seis acciones para un gobierno abierto:

1) crear mayor confianza en el gobierno;
2) garantizar mejores resultados al menor coste;

3) elevar los niveles de cumplimiento;

4) garantizar la igualdad del acceso a participar de la formulación de políticas públicas;

5) fomentar la innovación y las nuevas actividades económicas;

6) mejorar la efectividad mediante el aprovechamiento de los conocimientos y los recursos de los ciudadanos. (González, Juan, Sánchez, J. (2015: 51-73).

Según los autores Conde C., \& Gutiérrez, M. (2014: 237-256). México está avanzando en la implementación de estrategias estructurales en torno a las reformas en los campos del servicio civil profesional, la reducción de trámites en normas de regulación del Gobierno federal y el Gobierno en línea (OECD, 2011c). En la revisión de la OCDE para la gobernanza pública en México, estas tres Áreas de la administración pública fueron examinadas como instrumentos para fortalecer el buen Gobierno.

Para el caso mexicano, las conclusiones y recomendaciones de la OCDE fueron agrupadas de la siguiente manera (OECD, 2011c: 24-27):

- Las reformas administrativas deberán tener un rumbo estratégico y basarse en un enfoque integral de la gobernanza. Asimismo, requieren un enfoque de Gobierno general apoyado en la coordinación y en la comunicación entre las diversas organizaciones del Gobierno mismo.

- La capacidad de implementación es clave para una reforma administrativa exitosa.

- Es necesario crear una cultura de mejora continua, seguimiento y evaluación de los resultados de las reformas administrativas. Las reformas en los gobiernos subnacionales deben complementar los esfuerzos realizados a nivel nacional para generar 
un marco eficaz de gobernanza en diversos niveles.

- La mejora en el manejo y el desempeño del servicio público respalda los esfuerzos para apoyar el crecimiento económico y el desarrollo social.

\section{Conclusión}

En resumen el modelo de gobierno abierto en México, ha tenido avances significativos desde su nacimiento y sin duda cada uno de sus componentes son muy importantes para que se lleve a cabo esta práctica la cual considero que debería ser permanente en todas las instituciones gubernamentales de los tres niveles de gobierno, como señalan los autores que se citan en el presente artículo, y la manera en que se fue analizando cada uno de sus componentes, la transparencia desde su origen constitucional, así como la parte que le toca a los servidores públicos de presentar la información la cual debe se clara hasta las restricciones que se tiene en su publicación, en el componente de rendición de cuentas el cual es uno de los pilares del modelo señalado considero de los más importantes ya que a través de la rendición de cuentas, se puede evitar la corrupción, a través de este componentes es como las instancias fiscalizadoras exigen justificaciones a las entidades públicas y en caso de ser necesario aplicar sanciones, también la ciudadanía es por este componente que exige conocer el fin de los recursos públicos que realmente se utilizaron para el fin que fueron creados, el tercer componente analizado que es la participación ciudadana, cada vez se hace presente en las políticas públicas, la ciudadanía exige mayor transparencia y rendición de cuentas, cada vez se capacita más para exigir más y con el último componente que es la innovación por medio de cual la información del gobierno es electrónico mediante el uso de tecnologías de la información la relación entre el gobierno y la ciudadanía es más estrecha más a la mano de la población, es como a través de las páginas de internet se conoce toda la información pública. Todo esto logra que el gobierno sea más efectivo, eficiente, que se tenga mayor confianza en la información que se evite la corrupción y que la ciudadanía participe de manera proactiva y exija sus derechos constitucionales.

\section{Referencias:}

Alberto, J., \& Rodríguez, M. (2016). Transparencia: derecho fundamental y antídoto contra la corrupción. Revista de Derecho Puertorriqueño (55).

Arroyo Chacón, J. I. (2017). Innovación abierta como pilar del gobierno abierto Open innovation as a pillar of Open Government. Revista Enfoques, (27), pp. 13-41.

Conde C., \& Gutiérrez, M. (2014). La experiencia de la OCDE en la implementación de políticas de Gobierno Abierto. El desafío de la etapa de implementación. Revista Del CLAD Reforma y Democracia, 58(2), pp. 237-256.

González, J. \& Sánchez, J. (2015). La participación ciudadana como instrumento del gobierno abierto Citizen participation as a tool for open government. Espacios Públicos, 18(43), pp. 51-73. Recuperado de http://www.redalyc.org/pdf/676/67642415003.pdf

Loredo, J. de J. M. (2016). Transparencia y derecho a La Información pública en México. Avances, retos y perspectivas, pp. 14-26.

Martínez, M. (2014). Acceso a la información, transparencia y rendición de cuentas en México 37 años de evolución. El Cotidiano, (187), pp. 203-215. Recuperado de http://www.redalyc.org/articulo.oa?id=32531885013

Mashaw, J.L. (2016). Potential ACUS Statement Converning the ABA Proposal for amending the Administrative Procedure act. Recuperado de https://www.acus.gov/sites/default/files/documents/Ma shaw\%20Comments.pdf

Prieto-Martín, P.; Ramírez-Alujas, Á. (2014). Caracterizando la participación ciudadana en el marco del Gobierno Abierto Pedro Prieto-Martín y Álvaro Ramírez-Alujas. Revista Del CLAD Reforma y Democracia, (58), pp. 61-100. 
Quintanilla Mendoza, G. (2012). E-transparencia y Erendición de cuentas en los sitios web mexicanos. Espacios Públicos, 15(34), pp. 95-119. Recuperado de http://www.redalyc.org/src/inicio/ArtPdfRed.jsp?iCve= 67623463004

Ramírez, A. M., \& Alejandra, H. C. J. (2014). El sistema de rendición de cuentas Mexicano y su interacción con la archivística. Información, Cultura y Sociedad (ISSN 1514-8327) No. 30 (Junio 2014), pp. 79-104. Recuperado de http://search.ebscohost.com/login.aspx?direct=true \&db $=$ llf\&AN=96906431\&site=ehost-live

Ramos Tovar, M. E., Sieglin, V., \& Zúñiga Coronado, M. (2013). La intransparente transparencia...La asignación de sueldos y niveles académicos al profesorado en una universidad del norte de México. Perfiles Educativos, 35(141), pp. 26-45.

Rosales García, C. M. (2013). La regulación del derecho a la información pública en México. Ius Humani. Law Journal, $\quad 3, \quad$ pp. 113-137. https://doi.org/10.31207/ih.v3i0.35

Sánchez M. (2009). La participación ciudadana en la esfera de lo público. Espacios Públicos, 12(25), pp. 85-102. Recuperado de http://www.redalyc.org/articulo.oa?id=67611350006

Sandoval-Almazán, R. (2015). Gobierno abierto y transparencia: Construyendo un marco conceptual. Convergencia, 22(68), pp. 203-227.

Schedler, A. (2004). ¿Qué es la rendición de cuentas? In Instituto Federal de Acceso a la Información $y$ Protección de Datos (Ed.), Cuaderno de Transparencia, (03), pp. 5-37. Instituto Federal de Acceso a la Información y Protección de Datos.
Ugalde, L. C. (2003). La rendición de cuentas en los gobiernos estatales y municipales. In Cultura de la rendición de cuentas, pp. 5-51. Recuperado de https://www.asf.gob.mx/uploads/63_Serie_de_Rendici on_de_Cuentas/Rc4.pdf

Unión, H. congreso de la. (2008). Constitución de los Estados Unidos Mexicanos. Diario Oficial de La Federación, $8 . \quad$ Recuperado de http://www.diputados.gob.mx/LeyesBiblio/pdf/1_2708 18.pdf

USAID. (sin fecha). El Sistema Nacional Anticorrupción $y$ sus vínculos con el Sistema Nacional de Transparencia. Recuperado de www.snt.org.mx/images/Doctos/prop_libro_usaid_300 518_low.pdf

Villalpando, T., \& Andrés, E. (2009). La rendición de cuentas y La retórica de la nueva gestión pública, 12, pp. 71-89. Recuperado de http://www.redalyc.org/articulo.oa?id=67611167005> ISSN 1665-8140

Vera Martínez, M. C., Rocha Romero, D., \& Martínez Rodríguez, M. C. (2015). El modelo de gobierno abierto en América latina. Paralelismo de las políticas públicas de transparencia y la corrupción. Íconos Revista de Ciencias Sociales, 19(53), p. 85. https://doi.org/10.17141/iconos.53.2015.1565

\section{Páginas web}

INAI. (2019). Módulo 2 Gobierno abierto y transparencia en México. Recuperado de https://micrositios.inai.org.mx/gobiernoabierto/wpcontent/RELEASE/mod-02.html 